\title{
Development of professional creativity in the system of higher pedagogical education on the basis of independent activity
}

\author{
G.S. Camerilova ${ }^{1 *}, M . A$. Kartavykh$^{2}$, and E.L. Ageeva ${ }^{3}$ \\ ${ }^{1}$ Minin Nizhny Novgorod State Pedagogical University, Nizhny Novgorod, Russia \\ ${ }^{2}$ Minin Nizhny Novgorod State Pedagogical University, Nizhny Novgorod, Russia \\ ${ }^{3}$ Minin Nizhny Novgorod State Pedagogical University, Nizhny Novgorod, Russia
}

\begin{abstract}
The article considers the need to develop professional pedagogical creativity of future teachers as a leading trend in the modernization of higher education. The importance of creativity in the training of teachers is justified by modern humanistic tendencies of social development, which determine significant changes in the organization of the pedagogical process in schools. Innovations in the school education space impose special requirements on the personality of the teacher, updating his creative potential. The study defines the essence of the general category "creativity," based on which the idea of professional and pedagogical creativity is formed. As an important resource for its development, the independent activities of students are justified, which takes the form of leading activities in the system of higher pedagogical education. The work proposes a model for the development of vocational and pedagogical creativity based on creative independence on the example of the training direction "Pedagogical Education," the profile "Life Safety," the theoretical and methodological justification of which is presented by the highlighted principles. In their logic, targeted, meaningful, procedural, reflexive-evaluation components are built. A system of independent activities of students has been designed, uniting the algorithmic, reconstructive-heuristic, creative species that are used in the electronic educational environment of Minin University (MOODLE). The process of development of professional-pedagogical creativity is carried out sequentially and includes motivational-targeted, research, and reflectionevaluation stages. The diagnosis showed the effectiveness of the developed model in the conditions of its implementation in training practice.
\end{abstract}

\section{A problem statement}

Modern trends in the development of pedagogical education reflect the cultural meanings and realities of our era and set the humanistic vector for its development. The focus is on the personality of the teacher, his openness to innovation, creative independence, and

${ }^{*}$ Corresponding author: ipcs-profped@yandex.ru 
initiative, wide inter-object interaction. The insufficiency of traditional, previously effective, approaches to pedagogical education, associated with the dominant attitudes to master the basics of scientific knowledge, uniform and unambiguous requirements for the structure and organization of the learning process, becomes apparent. A new understanding of pedagogical education is revealed through the ideas of advance, openness, cultural similarity, humanistic value-sense parameters (V.A. Slastenin [1], A.A. Sidorova [2], A.P. Tryapitsyna [3]). The main attention is drawn to the personality of the future teacher, internally prepared and capable of adequate reaction to external socio-economic challenges, a situation of uncertainty, constant changes in the educational space, which requires the manifestation of thinking and activity beyond the boundaries of traditional ideas, that is, professional creativity. It is the professional creativity of teachers that can be considered as a "shock factor" of the innovative transformation of school life in its humanization, digitalization, strengthening an individual-personal approach in combination with communicativity. A creative teacher, able to develop new interesting and non-trivial methodological ideas and solutions, has emotional charge, initiative, improvisation, is ready for a variety of inter-object interactions. In the development of professional pedagogical creativity in the higher education system, the independent activities of future teachers play an invaluable role. Focused on creativity, it acts as an effective means of mastering the competencies defined by the federal state standard of higher education and, therefore, ensures the professional growth of graduates. There was a need to understand a new synthesis in the form of professional pedagogical creativity and the creative potential of the independent activities of students as a powerful reserve for the formation of the creative qualities of future teachers.

\subsection{The objective of the work}

The development of professional creativity in the system of higher pedagogical education based on independent activities was carried out based on the electronic educational environment (MOODLE) at the Nizhny Novgorod State Pedagogical University named after K. Minin (Minin University) within the training direction "Pedagogical Education," profile "Life Safety." The study was based on modern scientific ideas about the phenomenon of creativity, the development of which was greatly contributed by the works of both foreign and domestic scientists (J. Guildford [4], R. Turnberg [5], T. Lubart, K. Mishuru [6] D.B. Bogoyavlenskaya [7], T.A. Barysheva [8], T.V. Golubova [9], I.A. Malakhova [10], A.M. Matyushkin [11]. Their analysis indicates a great variety of interpretations of the conceptual essence of creativity. So, J. Guildford in the theoretical model of creativity reveals its essence through a structure characterized by the ability to see the problem, put forward various ideas to solve it, manifesting fluency, non-standard and original thinking, fantasy, imagination, inspiration. This complex is manifested in the form of divergent thinking, which is necessary for the development of a problem even before it is defined and there is no prescribed solution. In R. Sternberg's developed theory of investment, creativity is considered as a manifestation of various abilities (the ability to take risks, show tolerance to a situation of uncertainty, to overcome problems), and is characterized primarily as an intellectual ability associated with knowledge, a style of thinking formed in a creative environment. The essence of creativity in the representation of I.I. Malakhova is associated with thought processes that should be distinguished: divergence and convergence, fluency, flexibility, originality, abstraction, imagination, include fantasy and personal properties aimed at creative activity [10].

Despite differences in approaches, authors prioritize cognitive aspects in their definitions of creativity. The well-known domestic specialist D.B. Epiphany in her justifications draws attention to personal meanings and meanings, defines creativity as a 
deep personal property of a person, which is expressed in the original formulation and solution of a problem filled with personal meaning. The semantic emphasis of the definition allows us to consider the process of the development of creativity in the unity of the axiological, cognitive, and praxiological spheres of human subjectivity. The author notes that creativity is characterized by an intellectual initiative, the levels of development of which characterize the typology of creativity: stimulus-productive, heuristic, creative. Based on general conceptual approaches, the idea of professional creativity was formed (E.V. Markovich [12], A.V. Morozov [13], A.I. Popov [14], A.V. Tarakanov [15], V.G. Ryndak [16]), considered as the main feature of a creative personality. Various means of its development considered earlier are analyzed: innovative technological tools [17], research activities [18, 19], electronic educational environment [20, 21]. The analysis made it possible to conclude the multifaceted creative essence of professional creativity as the personal property of the future teacher, as well as about the possibilities for its development. Despite the existing experience, the issue of the formation of professional creativity among teachers in the higher education system is not sufficiently covered, and existing practice does not pay due attention to creativity, including when performing independent work. At the same time, in the literature, an opinion is formed about independent work as the highest form of an educational activity (N.V. Bordovskaya [22], I.Y. Zimnyaya [23], and in universities, following existing educational standards, independent work is given significant attention and priority, which significantly increases its total volume and specific importance in thematic plans and educational programs.

\section{Materials and the results of the research}

Development of professional creativity of future teachers in the system of higher education based on independent activities of students.

The theoretical analysis made it possible to draw up a general idea of professional pedagogical creativity and its composition. Professional creativity involves the formation of the creative individuality of the teacher since the most important feature of his modern activity is creativity aimed at developing the personality of students. For all the importance of the cognitive component, the creative potential of the teaching profession is the unity of motivational-value, cognitive, creative-activity aspects manifested in solving pedagogical problems. In this regard, its emotional-will qualities, communicativity, developed intelligence with a special type of divergent thinking are important, including the possibilities of producing a variety of alternative and parallel ideas, complementary and mutually exclusive positions based on associations, analogy, intuition. In conditions of significant transformations in educational organizations, professional creativity allows the teacher to implement innovative approaches, ensuring the introduction of promising pedagogical ideas, to translate into real teaching practices new forms of subject-subject relationships, scientific views, and teaching technologies.

Considered in the psychology of education as the "highest form of educational activity" (I.Y. Winter [23]), independent work acquires in the modern educational process a new status-leading organizational form of teacher training. Systematically participating in creative independent activities, students develop self-education skills necessary in the future profession. The productivity of independent work depends on the effectiveness of management, which includes planning the independent activities of students, its organization, motivation, and monitoring of results. In the course of work, the necessary operational coordination of activities takes place. At the planning stage, a model for the development of creativity was developed based on the creative independence of future teachers for the pedagogical direction of training, the profile "Life Safety." It reflects the fundamental theoretical and methodological humanistic ideas associated with the personal- 
active developmental nature of higher education, its dialogues, digitalization, contextuality, and the following principles:

- motivation as the most important component of the process of development of creativity among students of the future pedagogical elite, based on the belief in the personal and social significance of creativity in the pedagogical sphere;

- Freedom of creativity, ensured by the variability of pedagogical education in the field of life safety and the choice of an individual educational route following their interests and cognitive capabilities;

- The current level of training, determined by the available subject experience in solving pedagogical problems for ensuring safety, including, on an interdisciplinary basis: determination of the problem situation, hypothesis, selection of methods for its proof, experimental testing of the developed educational product;

- developing the possibilities of the electronic educational environment of Minin University, which organizes and manages independent activities by providing conditions for studying the composition of independent work on life safety, their problematic content, recommendations for implementation, evaluation criteria; comprehensive inter-entity interaction defined by interactivity;

- The contextual orientation of productive independent work, due to the pedagogical specificity of education in the field of life safety, and serving as a common platform for the integration of various pedagogical tasks, its systematizing and consistency;

- organizing and managing the productive independent activities of students, which is a powerful means of self-organization and a reserve for the development of professional creativity by including in the solution of new pedagogical tasks based on innovative technologies;

- structural differentiation of independent tasks: on the content of education in the field of life safety, the level of the problem, independence of performance, the productivity of upcoming pedagogical activities, forms of implementation;

- pedagogical support for independent activities, consisting of creating organizational and pedagogical conditions for the successful development of professional creativity, providing psychological support and the mood of students for success, counseling, helping in choosing pedagogical means for solving the problem, forms of presentation, reporting, reflection.

Based on the isolated theoretical and methodological basis of the model, its target, meaningful, procedural, reflexive-evaluation components were determined. The target component was to develop the professional pedagogical creativity of students based on performing independent activities in the field of security. The content component was designed using a personal-activity approach and involved the inclusion of future teachers in independent work to fulfill tasks in the field of life safety. Life safety, as a rapidly developing scientific field of knowledge and educational sphere, has high and growing significance, revealing the issues of ensuring the security of the person, society, and the state. Here, based on humanistic traditions, interdisciplinary, problematic, ideas of health saving, general laws of dangerous phenomena, and emergencies of a natural, man-made and social nature, methods of protection against them are considered; basic military service, first aid to victims, and healthy lifestyles. Life safety education is a response to the challenges of various internal and external threats and instability occurring in society. A promising teacher must himself have a culture of safe behavior and form it among his pupils. At the same time, in schools, a formal attitude to this discipline and irresponsibility to hazards have been preserved. A creative teacher can change the situation, whose independent training at the university was carried out in a creative vector.

The structural species diversity of the independent activities of students at the university seems multidimensional. We singled them out according to the following criteria: (a) the 
logic of deploying the scientific content of life safety education; b) productivity levels of future pedagogical activity (N.V. Kuzmina): low-productivity with a predominance of reproduction and adaptability; medium-production with possession of locally modeling training strategies; highly productive, with systemically modeling activities in the field of personal formation of students through their subject; c) problem levels of tasks based on the use of partial search, heuristic and research methods; d) self-activity levels: low, when the teacher himself formulates the problem and helps students to solve it; medium, in case of self-solution of the problem formulated by the teacher; high - independent setting and solution of the problem. By systematizing the obtained groupings, we created a general structure of independent activity, represented by three groups: 1) traditimic; 2) reconstructive-heuristic, 3) creative.

In the framework of an algorithmic activity comparable to the problem level of the partial search type, students, showing ordinary activity, perform problem tasks, mainly according to the proposed samples, assimilating scientific methods and techniques basic for the development of creativity. Among them: compiling a comparative table: common features and differences of design and research activities in life safety training, "the thematic thesaurus" Methods of training, "a cluster of concepts" Methodological system of training in the field of life safety. " Activity within a given mode of action, with the predominance of external motivation, is associated with an incentive-productive level of creativity.

A reconstructive-heuristic independent activity with a heuristic level of problem is characterized by an increased level of activity not stimulated by external factors in fulfilling pedagogical tasks for transformation, as well as an analysis of unfamiliar problematic pedagogical situations. Going beyond common solutions means taking the initiative to find a new original; perseverance, and perseverance. The student independently comes to empirical generalizations, characterizing the heuristic level of creativity. Successful independent work on creating variable models of a modern lesson on life safety or assessing social security at school indicates a progressive movement of students towards professional creativity.

The creative independent activity itself is distinguished by high intellectual activity in solving pedagogical problems in innovative educational conditions (digitalization of education in the field of life safety, dialogical interaction of educational subjects, technological tools of the educational process). It involves the development of alternative and complementary ideas and approaches, diverse, at first sight, solutions. Students enthusiastically develop innovative issues, independently building a program of pedagogical actions, selecting methods for their implementation, indicating future problem situations. The independently identified pedagogical problem is considered as a happy event, and its production is considered as the most important factor in the highest manifestation of creativity - creativity. Independent work is carried out in conditions of high self-organization and operability. Graduates are prone to self-reflection and selfesteem of the obtained pedagogical result and ways to achieve it. Due to reflection, personal development is carried out in the direction of professional creativity.

The organization of the process of independent activity provided for the allocation of its stages, as well as the creation of educational and methodological support, which includes a program disclosed in the electronic educational and methodological complex. Differentlevel tasks are distributed in blocks and are accompanied by methodological recommendations for their implementation and evaluation, provided for by the evaluation funds fund.

The procedural component includes:

1) an organizational motivational-target stage, the tasks of which include: motivation as a positive attitude to intellectual activity, an internal desire for creativity that has personal 
meaning, and the conscious importance of solving security problems for the future profession, leading to goal-setting. The achievement of this goal requires the assessment of educational resources necessary to solve the problem and the creation of an individual program of action, based on the current competencies of students;

2) a search and research stage, which includes performing independent tasks of different levels of the pedagogical problem under its educational route, reflected in individual planning. When the conditions of strength, concentration, and passion and excitement coincide, there is a complete immersion in an activity, and pleasure is achieved not only by the upcoming result but also by the process of creativity itself, the discovery of a new one. In solving pedagogical problems, the use of not only logical methods of objective analysis, systemic comparison, but convincing argumentation of the identified causal relationships is also welcomed. An essential role is played by intuition and the search for original and unusual techniques, for example, model representations, conditionally, generically, and clearly showing the complex structure and relationships of pedagogical phenomena (a cluster of game technologies in life safety training). Creative in its essence is the use of "smart images" (V.V. Rubtsov), the verbal fixation of which is symbolic metaphors ("system elevator" in the development of the methodological system of the lesson). Presenting the result of the creative transformation of cognitive and emotional experience, "smart images" symbolically and reflect theoretical constructions, providing their deeper understanding (branching tree is a metaphor for divergent thinking); Coordination of independent activities is carried out in the course of work, as well as in pedagogical practice.

3) The final reflexive evaluation stage consists in the analysis of the completed educational product (mini-study on victimological prevention at school, the scenario of the extra-time event "Immortal Regiment," a quest for a healthy lifestyle, the portfolio "My Achievements," in which the specific features of a creative teacher are manifested), its presentation and assessment. It should be noted that reflection is carried out after each stage, forming an idea among future teachers of themselves as a subject of their creative activity, the success of their progress on the path to gaining creativity. Understanding the self-performed activity, that is, performing introspection, the student evaluates its performance to make the necessary adjustments in the future. Even failed attempts to solve independent pedagogical problems can serve as a lesson in building new more rational and effective ways to achieve goals. In the course of reflection comes an understanding of new values of life safety and educational prospects, an awareness of the need for the divergence of thinking in solving pedagogical situations, worldview ideas from the points of view of innovation, tolerance, creativity.

Diagnosis of the development of professional creativity in future teachers was carried out based on analysis and assessment of the degree of intellectual activity and motivation in three levels: stimulus-productive, empirical, and creative. The stimulus-productive level of creativity, characteristic of traditimic independent activity, is distinguished mainly by external motivation, and actions of intellectual activity that do not go beyond the specified method, but are performed in good faith and responsibly. The heuristic level of creativity is characterized by reconstructive-heuristic independent activity with internal motivation and solving pedagogical problems that require the restructuring of techniques and methods, the manifestation of an initiative to search for new approaches. The creative level of creativity is manifested in creative independent activity, characterized by stable internal motivation, high intellectual activity to solve problems in conditions of uncertainty, an initiative in the development of new educational situations to ensure life safety.

Experimental data showed a noticeable development of creativity in students, So, at the initial stage of the experiment, $48 \%$ of students were registered at the stimulus-productive level, $42 \%$ on heuristic, $10 \%$ on creative; at the end of the experimental work, these data 
amounted to $20 \%, 57 \%, 23 \%$, respectively. An increase in activity to creative types of independent activity and creative approaches was revealed, in the conditions of emergencies in the field of life safety education. An independent means of assessing the development of creativity of future teachers is testing, which includes the Venker creativity test technique [24]. With its help, a coefficient and a creativity profile were determined. At the first stage, the coefficient of creativity was determined. Trainees responded to each of the 48 proposed statements. Five options were suggested: (1) Fully agree; 2) agrees; 3) I find it difficult to answer; 4) disagree; 5) completely disagree. Each variant corresponds to a quantity of 5 to 1 . The obtained creative factors are considered as the sum of points for answers to all statements. The larger it is, the higher the creative coefficient with an average of 100 points. The totality of the results obtained was divided into three groups reflecting levels of creativity: 1) high - more than 120 points; 2) average: from 80-120 points; 3) low less than 80 points. In general, positive dynamics in the development of creativity among students in performing independent activities were noted. If at the initial stage a high level of creativity was observed in slightly more than ten percent of respondents $(12 \%)$, then by the end of training it more than doubled $(25 \%)$. The average level of creativity has increased significantly: from $42 \%$ to $57 \%$. As for the low level, the dynamics of the decline from $46 \%$ to $18 \%$ is considered by us as a positive result. The established trend corresponds to the opportunities of the student age, professional needs, and aspirations of the youth audience.

At the second stage, a creative profile was established, showing the creative orientation of the person, the versions of which were proposed by the Venker method:

1) type A - lovers of discoveries;

2) type B - critical;

3) type C - strategically thinking;

4) type D - analytically thinking;

5) type E - diligent;

6) type F - needing harmony;

7) type $\mathrm{G}$ - inquisitive;

8) type $\mathrm{H}$ - sensual. Analysis of the obtained data made it possible to conclude that the maximum three quantitative indicators for creativity profiles are as follows: critical $-22 \%$, analytically thinking $-20 \%$, discovery lovers $-15 \%$. Strategically thinking $-12 \%$, needing harmony ( $8 \%)$, sensual $(7 \%)$, the rest $(6 \%)$ demonstrated a diligent and inquisitive type of creativity. The data obtained as a result of testing are generally correlated with the obtained indicators of creativity levels, taking into account motivation and intellectual activity.

\section{Conclusions}

The professional creativity of the teacher is the most important factor in the modern development of general education. In this regard, its relevance is evident and reflected in modern standards of higher education. The competencies planned for the development focus on creativity and creativity, an important condition for the development of which is the independent activities of future teachers. The developed model for the development of creativity based on the independent activities of students in higher pedagogical education is built in the logic of humanistic traditions. They are implemented in the ideas of competent, personal-activity, context-based approaches, large-scale digitalization. The proposed system of independent activity of students in the field of training "Pedagogical Education," the profile "Life Safety" integrates traditimic, reconstructive-heuristic, creative types. Each of the proposed types of independent activities includes a block of tasks corresponding to a different level of creativity: stimulus-productive, heuristic, creative. The process of creativity development consists of stages: organizational motivational - targeted, search and 
research, final reflexive-evaluation, as they pass, the development of professional pedagogical creativity takes place. The diagnosis carried out in various ways confirmed the possibility and effectiveness of developing the professional creativity of students at a pedagogical university in the process of performing independent activities.

\section{References}

1. V.A. Slastenin, Pedagogical education: challenges of the XXI century. Report at the International Scientific and Practical Conference "Pedagogical Education: the Challenges of the 21st Century», p. 48 (2010)

2. A.A. Sidorova, Higher education in modern Russia: state strategy/Moscow State University named after M.V. Lomonosov. Faculty of Public Administration, p. 192 (2015)

3. A.P. Tryapitsyna, Modern trends in the development of the quality of pedagogical education. Man and education. Academic bulletin of the Institute of Pedagogical Education and Adult Education of RAO, 3 (32), 4-10 (2012)

4. J. Guildford, Three sides of intelligence. Psychology of thinking, p. 32 (1965)

5. R. Sternberg, Practical intelligence, p. 272 (2002)

6. T. Lubart, K. Mishuru, Psychology of creativity, p. 215 (2009)

7. D.B. Bogoyavlenskaya, Psychology of creative abilities, p. 320 (2002)

8. T.A. Barycheva, Psychology of the development of creativity: theory, diagnostics, technology, p. 316 (Monograph. St. Petersburg. VVM, 2016)

9. V.M. Golubova, Development of creative economy and creativity. Basic research, 25;URL: http://www.fundamental-research.ru/ru/article/view?id=36985.

10. I.A. Malakhova, Development of creativity of students and students as an educational strategy of the modern education system , IDE-OnlineJournal, $3 \mathrm{https} / / \mathrm{www}$. idejournal. org/article (2016)

11. A.M. Matyushkin, Thinking, training, creativity, p. 720 (Moscow, 2003)

12. E.V. Markovich, Pedagogical creativity and the pedagogical component structure of pedagogical identity, https://nsportal.ru/blog/pobsheobrazovatelnayatematika/all/2012/11/08/Pedagogical creativity-as-leading (2012)

13. A.V. Morozov, Creativity as the basis of innovative activity and professionalism of the modern leader Psychology in economics and management (2014)

14. A.I. Popov, Development of professional creativity in the higher education system, Continuing pedagogical education: problems and searches, 1, 50, URL: http://kpfu.ru/psychology/programma-razvitiya-ipo-kfu (2016)

15. A.V. Tarakanov, Development of student creativity using active methods of study at the university, Siberian Pedagogical Journal, 2, 65-68 (2012)

16. V.G. Ryndak, Pedagogy of creativity, 284 (Monography. Moscow, 2012)

17. G.S. Kamerilova, M.A. Kartavykh, E.L. Ageeva, I.A. Gordeeva, M.A. Veryaskina, Development of Professional Creativity of Teachers in the System of Professional Safety Culture of Children in Transport, Lecture Notes in Networks and Systems, 91, 446-451 (2019)

18. N.I. Astashina, G.S. Camerilova, Research environmental activity as a resource for the development of professional creativity in the conditions of an innovative strategy of higher education, The azimuth of scientific research, 2 (27), 8-22 (2019) 
19. G.S. Camerilova, M.A. Kartavykh, Development of creativity based on the research activities of students in the study of geography, Geography at school, 4, 21-28 (2019)

20. G.S. Camerilova, M.A. Kartavykh, Development of vocational and environmental creativity in the digital educational environment of the university. Environmental education for sustainable development: theory and pedagogical reality, 12-15 (2019)

21. S.M. Markova, A.K. Narkaziev, Methodology for the study of the content of vocational education, Vestnik of Minin University, 7, 1, 1, URL: https://doi.org/10.26795/2307-1281-2019-7-1-2 (2019)

22. N.V. Bordovskaya, Research potential of a student, p. 264 (Monograph. Moscow, Rusines, 2015)

23. I.A. Zimnyaya, Competent approach in education, Materials of the XIV All-Russian Meeting, 2, 6-12 (2004)

24. K. Venker, Kreativ Test «WiekreativsindSie?». Deutschland, Forum für Politik, Kultur und Wirtschaft, 6 (12-1), 64-66 (2004) 